\title{
Un melómano en la guerra: Alejo Carpentier, corresponsal de la Guerra Civil Española*
}

\author{
A Melomaniac at War: Alejo Carpentier, \\ Correspondent in the Spanish Civil War
}

\author{
JESÚS CANO REYES \\ Universidad Complutense de Madrid, Facultad de Filología. España. \\ jesuscanoreyes@ucm.es
}

En julio de 1937, Alejo Carpentier viaja desde París a una España sumida en plena Guerra Civil que sin embargo celebra con éxito el II Congreso Internacional de Escritores para la Defensa de la Cultura. Este artículo estudia el papel de Carpentier como corresponsal de guerra a partir de su reportaje "España bajo las bombas", contextualizándolo en la producción intelectual de su tiempo. El examen del texto revela una singularidad -la abundancia de referencias sonoras y musicales, llamativa en el contexto bélico pero nuclear en la escritura de Carpentier- y una experiencia común con otros corresponsales -el complejo de inferioridad del intelectual que se compara con el soldado-. Por último, ahondo en "España bajo las bombas" como palimpsesto de su novela posterior $L a$ consagración de la primavera (1978).

Palabras clave: Alejo Carpentier, Guerra Civil Española, Corresponsal, Crónicas, Música.

In July 1937, Alejo Carpentier travels from Paris to a Spain which, despite being inmersed in a Civil War, is succesfully holding the Second International Congress of Writers for the Defence of Culture. Taking his report "España bajo las bombas" as a starting point, this paper studies the role of Alejo Carpentier as a war correspondent within the context of the intellectual production at the time. A close examination of the text reveals a peculiarity -the large number of sonorous and musical references, remarkable in warlike context but fundamental in Carpentier's writing- and a shared experience with other correspondents -the intellectual's inferiority complex who compares himself with the soldier-. Finally, I delve into "Espana bajo las bombas" as a palimpsest of his later novel $L a$ consagración de la primavera (1937).

Key words: Alejo Carpentier, Spanish Civil War, Correspondent, Chronicles, Music.

\footnotetext{
"Este trabajo ha sido posible gracias al proyecto de investigación "El impacto de la guerra civil española en la vida intelectual de Hispanoamérica”, financiado por el Ministerio de Economía, Industria y Competitividad de España (FFI2015-65817-P).
} 


\section{PRELUdiO: UN REPORTAJE DIFERIDO}

España es un motivo reincidente en la escritura de Alejo Carpentier, tanto en su obra literaria como en la periodística. Instalado en París desde 1928, el cubano viaja a España en varias ocasiones: en Madrid publica su primera novela Écue-Yamba-O en 1933, y regresa al año siguiente para asistir al estreno de Yerma, de Federico García Lorca ${ }^{1}$. Estos viajes iniciales han de inspirar textos como, por ejemplo, las "Crónicas de un viaje sin historia” (tres crónicas publicadas en la revista cubana Carteles en enero y febrero de 1934) o "Bajo el signo de la Cibeles" (aparecida también en Carteles en septiembre de 1934)².

Durante la guerra, Carpentier regresa a España una vez más, en esta ocasión para asistir en julio de 1937 al Segundo Congreso Internacional de Escritores para la Defensa de la Cultura (conocido como el Congreso de Escritores Antifascistas); sería su quinto viaje en este período (Buscaglia 2004: 24). Más allá del contexto estrictamente español, conviene matizar el momento histórico y político en el que se celebra el II Congreso Internacional de Escritores para la Defensa de la Cultura de 1937, así como su antecedente parisino de 1935. Manuel Aznar Soler ha estudiado detenidamente ambos congresos como el fruto de la política de Frente Popular adoptada por la Komintern en Moscú en 1935. Una de las estrategias nucleares de esta política, liderada por Willi Münzerberg, es la promoción de los congresos internacionales -lo que conlleva el reclutamiento de escritores y artistas- como parte de la lucha contra el fascismo (Aznar Soler 1987: 15-20).

Carpentier llega a Barcelona a últimas horas de la tarde del día 3, en un grupo que incluye a André Malraux, Claude Aveline, Niccola Potenza, Stephen Spender, Pablo Neruda, Octavio Paz, Carlos Pellicer y los también cubanos Juan Marinello, Nicolás Guillén y Félix Pita Rodríguez (Schneider 1978: 55-56). Después de recorrer Valencia, Madrid, Valencia de nuevo y Barcelona, Carpentier debe de formar parte de la delegación de escritores que cruza la frontera de Port Bou a Cerbère la noche del 13 de julio, cumpliendo así diez días de viaje por la España en guerra ${ }^{3}$. El resultado de esta incursión en el país es el reportaje "España bajo las bombas", que se publica en la revista Carteles en cuatro entregas entre septiembre y octubre de 1937.

\footnotetext{
${ }^{1}$ En un artículo de prensa escrito durante la guerra, Carpentier recuerda un incidente sucedido en este estreno que presagia de algún modo el conflicto: "La noche en que un público modesto y ferviente había llenado el teatro en que se estrenaba Yerma del inolvidable Federico, unos cuantos señoritos lacayos de Gil Robles se permitieron organizar un 'pateo'... que se terminó, por suerte, con un pateo en sus asentaderas" (Carpentier 1938: 26).

${ }^{2}$ El mismo Alejo Carpentier afirma que, pese a que las crónicas escritas desde París y publicadas en Carteles entre 1928 y 1939 han de someterse a las limitaciones que impone una revista no literaria, "las que se refieren a viajes a España, Bélgica, ciudades de Francia, etcétera, no son del todo malas” (Arias 1977: 20-21).

${ }^{3}$ Por tanto, es una exageración cuando al comienzo de "España bajo las bombas" habla de "estos veinte días de viaje a una tierra sometida" (Carpentier 1979: 134).
} 
Es necesario tener en cuenta que Carpentier no es un corresponsal al uso, puesto que no puede reconocerse en él el prototipo de enviado especial que parte en un viaje de ida y vuelta y desde su destino temporal escribe y envía los textos para su publicación en el país de origen. En primer lugar, Carpentier reside en un tercer país, Francia, al margen de la ruta que une a España y Cuba. En segundo lugar, Carpentier escribe su reportaje a posteriori, incumpliendo por tanto la característica de la inmediatez, que pretende el mínimo intervalo entre los sucesos y su escritura. Por último, Carpentier ni siquiera declara perseguir la esquiva objetividad que suele formular la mayoría de los periodistas; en lugar de presentarse como un testigo objetivo que informa puntualmente de los hechos sin permitirse la valoración personal, comienza reconociendo que, frente a los sucesos de Espańa, "nuestra 'lógica del pensamiento' se ha roto ante nuestra 'lógica del corazón”" (Carpentier 1979: 134). Aunque justo después declare que se propone llevar "una especie de cámara fotográfica destinada a fijar lugares y gentes, así como un micrófono para recoger palabras y sonidos" (Carpentier 1979: 134), la voz narrativa está lejos de funcionar como una máquina registradora. Al contrario, predominan en el texto las reflexiones personales y las anécdotas. Como afirma Gnutzmann, "tratándose de un reportaje sobre el II Congreso, el lector apenas se entera de los eventos ocurridos en él”, pese a lo cual, "(n)o es difícil entender que al gran público cubano en 1937 seguramente no le interesara el congreso sino el ambiente de la España en guerra” (Gnutzmann 1986: 180). Desde luego, el interés sobre los discursos de previsible mensaje y las peripecias de un grupo de intelectuales trasladados de hoteles a auditorios es eclipsado por otras historias de atractivo calado humano. Curiosamente, Carpentier, que ha dejado posteriormente una imagen de avezado orador, es uno de los pocos que no toman la palabra públicamente durante las sesiones del Congreso.

En 1964, César Leante recoge unas declaraciones del autor en las que hace balance de su lejano viaje a Espańa del siguiente modo:

En 1937 volví a España también, pero en circunstancias muy distintas como ya dije. Había estallado la guerra civil. Se peleaba en las calles de Madrid. La Maison de la Culture, que dirigía Louis Aragon, convocó a un Congreso de Escritores en Madrid. Integraban la delegación cubana Marinello, Nicolás Guillén, Pita Rodríguez, Leonardo Fernández Sánchez y yo. Yo viajo desde París con César Vallejo, Malraux, Marinello y Pita. En Valencia recibimos nuestro bautismo de fuego la misma noche que llegamos; la aviación fascista bombardeó la ciudad; las bombas estremecían el hotel. Mi compañero de cuarto dormía en la cama sin hacer caso de las bombas. "No va a pasar nada", me dijo, y volvió a meterse debajo de la colcha. Era el escritor Lukács. Madrid estaba cercada por los moros, se combatía en la Ciudad Universitaria y todos los campos que rodeaban la capital estaban atrincherados. Los bombardeos eran diarios; tres veces al día, indefectiblemente, venía a bombardear la aviación de Franco. Bajo ese clima se efectuó el Congreso, que fue un llamado a la defensa de Espańa, a la libertad y a la lucha contra el 
fascismo. Los intelectuales del mundo intentaron alertar la conciencia del hombre contra el peligro que se avecinaba (Arias 1977: 65-66)4.

En 1978, tras recibir el Premio Cervantes y alcanzar su consagración como escritor e intelectual, Carpentier publica La consagración de la primavera, novela cuya acción da comienzo en torno a la Guerra Civil Española y el papel desempeñado en ella por los combatientes extranjeros: en ese momento histórico comienza el puente que desembocará décadas después en la Revolución cubana. En buena medida, las páginas dedicadas a la guerra de España se construyen a partir de las vivencias del autor reflejadas en "España bajo las bombas".

La escritura de Alejo Carpentier acerca de la Guerra Civil Española va más allá de las citadas novela y crónica. Como el resto de intelectuales, su labor de lucha la realiza en las trincheras de los distintos periódicos y revistas. Hasta donde sé, Carpentier escribe tres textos más durante los años 1936-1939 con temática española. En el artículo "Los defensores de la cultura", escrito antes de su viaje al Congreso y aparecido en el boletín Nuestra España de París en marzo de 1937, Carpentier responde a quienes atacan a la República acusándola de destruir el patrimonio artístico del país. Para ello esgrime algunas anécdotas, ya sean presenciadas por él mismo o narradas por testigos, con el fin de dar la vuelta a esos argumentos. Comienza rememorando un viaje a Cuenca, donde el culto al arte en una iglesia constituye un ejemplo del "respeto del admirable pueblo español por las obras y hechos de la cultura"s:

Mientras los reaccionarios bombardean ciudades con sádico encarnizamiento, mientras ponen en práctica el chantage que consiste en refugiarse precisamente en alcázares seculares e iglesias veneradas por los arqueólogos, son los milicianos, los

\footnotetext{
${ }^{4}$ La memoria "es una gran y sutil fingidora", dice John Banville al comienzo de su novela Antigua luz (Banville 2012: 13). ¿Por qué "confiesa" Carpentier, cuarenta años después de los sucesos, que su compañero de habitación había sido el húngaro Máté Zalka, alias General Lukács, impávido ante las explosiones? El relato de su reportaje "España bajo las bombas", menos audaz y fantasioso, ha de ajustarse más a la verdad: "De pronto una explosión sorda, subterránea, formidable golpe de ariete en la corteza del suelo, hace temblar las paredes del hotel... Sacudo a Pita Rodríguez, mi compañero de habitación, que duerme como un bendito. [...] Nos reunimos con los otros inquilinos del hotel, bajando apresuradamente al hall' (Carpentier 1979: 151). ¿¿Pretende Carpentier adornar de épica la narración o su memoria ha ido transformando con sucesivas capas de ficción la propia historia? Seguramente haya una mezcla de ambas razones. Por otra parte, junto a la verosimilitud de que el cubano compartiera habitación con el compatriota que lo acompańa durante todo el viaje, en lugar de hacerlo con una figura admirada pero desconocida y ajena, hay otra circunstancia a considerar: desdichadamente, el General Lukács lleva muerto un mes, desde que una bomba alcanzara su vehículo en el camino hacia Huesca (el escritor alemán Gustav Regler, que lo acompańa, es herido pero sobrevive).

${ }^{5}$ La crónica de ese viaje a Cuenca, realizado dos años atrás, se publica en Carteles el 29 de diciembre de 1935 bajo el título "En la ciudad de las casas colgadas". En ella, alude precisamente a la existencia de estas iglesias clausuradas: "Hay en Cuenca misteriosas iglesias cerradas, en las que nunca se dice misa, y que sólo pueden visitarse gracias a la amabilidad de quienes están encargados de su cuestión [sic]" (Carpentier 1979: 131-132).
} 
hombres del pueblo, los que se afanan por conservar un patrimonio cultural que será su bien propio en un próximo futuro (Carpentier 1937: 1).

Otra anécdota, ya durante la guerra, sirve para elogiar el comportamiento del pueblo, concienciado de que los intelectuales no deben arriesgar su vida pues su arma es otra: la palabra. Así, un miliciano interpela a Rafael Alberti en Madrid para animarle a ponerse a salvo marchándose a Valencia: "Los milicianos somos muchos, los sabios y los poetas son pocos... Sálvense... y escriban para nuestros hijos..." (Carpentier 1937: 1-2). La misión del intelectual y la función de la escritura serán tratadas en páginas posteriores.

En julio de 1938, aparece en la revista Mediodía de La Habana un extenso artículo titulado “iAbajo la inteligencia! ¡Viva la muerte!”, que parte del exabrupto de José Millán Astray en el Paraninfo de la Universidad de Salamanca ${ }^{6}$ para ahondar en el tópico de las dos Espańas: "una grande, creadora, auténtica", representada por los "españoles lúcidos de nuestro siglo": Valle-Inclán y Unamuno, pese a que este último "hubiese tenido la debilidad de equivocarse"; y otra España que "representaba los intereses mezquinos de castas y hombres apoyados en la ambición personal de generales traidores". A causa de este último grupo, muy minoritario (dice Carpentier), ha tenido lugar el alejamiento entre Espańa y las naciones americanas; es por él que "tuvimos en otros tiempos tantos prejuicios contra Espańa, nosotros, latinoamericanos" (Carpentier 1938: 14). Sin embargo, eso ha cambiado con la guerra y ahora es nuevamente más corta la distancia entre las dos orillas.

Tras once años en París, Carpentier regresa a La Habana en 1939. Allí publica, en agosto de ese año, "La muerte de Miguel Hernández", una necrológica del poeta de Orihuela. En la primera parte, realiza un perfil del personaje al tiempo que intercala algunos de sus versos; en la segunda parte, desvela que en su estudio de grabación de París, en 1938, ha registrado "el timbre varonil y profundo de su voz" recitando uno de sus poemas?: "Esa voz la he apresado. La tengo aquí, en La Habana, en mis maletas" (Carpentier 1939: 36). Carpentier describe a Hernández fascinado con los instrumentos y las luces -rojas y azulesdel estudio, con la tecnología del sonido. Además del valor histórico de la anécdota, el texto necrológico tiene un interés ańadido en tanto se recuerda que, en realidad, en 1939 Miguel Hernández sigue vivo, aunque la noticia de su falsa muerte se haga tristemente real poco tiempo después (morirá en marzo de 1942).

\footnotetext{
${ }^{6}$ Me refiero naturalmente a la conocida disputa con Miguel de Unamuno el 12 de octubre de 1936, Día de la Raza, cuando el militar, ante las contundentes palabras de censura del intelectual vasco, profiere enajenado el grito de “iMuera la inteligencia!”. La mujer de Franco, Carmen Polo, tiene que salir con Unamuno para evitar una desgracia.

7 Se trata de la "Canción del esposo soldado", aunque Carpentier se refiere al poema como "La novia del soldado". Esa misma grabación con la voz de Miguel Hernández puede escucharse en Internet: http://www. youtube.com/watch?v=5tIr1Inh37E. [Consultado a fecha de 1 de marzo de 2017]. Para profundizar en las relaciones de Miguel Hernández con los escritores cubanos, puede consultarse el ameno libro de Amado del Pino y Tania Cordero Los amigos cubanos de Miguel Hernández.
} 


\section{PRIMER MOVIMIENTO: LA GUERRA ESCUCHADA}

Relacionar la obra literaria de Alejo Carpentier con la música está lejos de ser una propuesta osada o novedosa. Para cualquier lector resulta evidente que sobre su estilo ejercen las reglas de una armonía y un ritmo que confieren al oleaje de su prosa movimientos de gran musicalidad. Pero además, tanto en el plano temático como en el plano estructural, la música vertebra la escritura carpenteriana y se funde con ella en su más íntima esencia. En Los pasos perdidos (1953), la música ostenta una función nuclear, pues el tema del libro no es otro que la búsqueda de los orígenes de la música a través del viaje a la selva de su protagonista. Concierto barroco (1974) es, ya desde el título, una celebración de la música (y del mestizaje, hito ineludible del pensamiento de Carpentier): amén de numerosos motivos menores, la trama central gira en torno al concierto improvisado entre Vivaldi, Scarlatti y Haendel, donde se cuela el esclavo cubano Filomeno, y a la puesta en escena de la ópera Montezuma de Vivaldi ${ }^{8}$. En La consagración de la primavera (1978), el leitmotiv musical ostenta una función medular gracias a la protagonista Vera y su espectáculo de danza basado en la obra de Stravinsky; a ello hay que sumar la relación con la música de otros personajes de menor trascendencia, como las compañías de bailarines, el trompetista Gaspar o la primera mujer de Enrique, que es musicóloga.

Asimismo, tradicionalmente se ha considerado que la construcción de las novelas de Carpentier se halla regida por patrones musicales, como si el universo carpenteriano cumpliera la imagen pitagórica de la música de las esferas. Según esta lectura, El acoso (1956) reproduciría cabalmente el molde de una sonata, comparación refrendada por el aserto de su autor: "está estructurada en forma de sonata: primera parte, exposición, tres temas, diecisiete variaciones y conclusión o coda" (Arias 1977: 67)9. El mismo Concierto barroco parece jugar con la estructura y reproducir las formas del concerto grosso que se celebra en la novela: Marina Gálvez despliega un juego de equivalencias entre los movimientos de la novela y los de la composición musical (Gálvez Acero 1978: 539-553); por otra parte,

\footnotetext{
${ }^{8}$ Además, no debe olvidarse la ostensible musicalidad en el nivel fónico con las aliteraciones y paronomasias que inauguran el texto: "De plata los delgados cuchillos, los finos tenedores; de plata los platos donde un árbol de plata labrada en la concavidad de sus platas recogía el jugo de los asados; de plata los platos fruteros, de tres bandejas redondas, coronadas por una granada de plata..." (Carpentier 1974: 9). El lenguaje es sensualidad, es música.

${ }^{9}$ En apoyo a esta búsqueda de correlación entre las estructuras literarias y las musicales, Carpentier publica en fechas próximas (8 de noviembre de 1955) un artículo en El Nacional de Caracas titulado "Novela y música", donde propone la adopción para el género novelístico de una "disciplina formal" del mismo modo que la música se sujeta a determinados moldes "sin perder por ello la libertad creadora": “¿No sería interesante que, en ciertos casos, los novelistas trabajaran dentro de una forma determinada, como tan naturalmente lo hacen los músicos, tratando de compactar lo creado en un bloque sin fisuras?... La literatura actual nos ofrece ya más de un ejemplo de esa preocupación que parece responder a una honda necesidad del espíritu" (Carpentier 1987: 96-97). En otro trabajo, "Lenguaje y música", reflexiona sobre la similar condición esencial de ambos sistemas de comunicación: "Al fin y al cabo, el origen de la música está en la voz humana, como el idioma" (Carpentier 1987: 77-79).
} 
Leiling Chang encuentra en las reiteraciones y en una estructura tripartita no tan evidente una respuesta "a las leyes estructurales del arte musical" (Chang 2002: 183). Antonio Benítez Rojo halla un "paralelismo estructural" entre el Canon Perpetuus de Bach y el cuento "El camino de Santiago" (1958), cuyo texto "deviene en mito o en música; en juego de significantes; en acorde astral" (Benítez Rojo 1983: 30). Incluso, el cuento "Viaje a la semilla" (1958), dividido en pequeños fragmentos, correspondería al equivalente en prosa de la experimentación con la armonía que lleva a cabo la música dodecafónica de Arnold Schönberg, defendida en la época por Carpentier (Acosta 1981: 22-23).

En esta línea hermenéutica, el libro de Leonardo Acosta, Música y épica en la novela de Alejo Carpentier, interpreta calurosamente la existencia de una correlación entre las creaciones literarias y unos predeterminados modelos musicales:

Pero nuestro novelista [...] parece inspirarse en las formas musicales -grandes y pequeńas- no sólo con el fin deliberado de dar a sus novelas y narraciones cortas la deseada coherencia estructural, sino para lograr también otros objetivos, que a grandes rasgos podemos resumir en uno fundamental: conseguir, a través de formas empleadas por el arte musical, el ajuste perfecto entre el tema y su forma expresiva, trascendiendo al mismo tiempo los esquemas tradicionales de los distintos géneros literarios (Acosta 1981: 16) ${ }^{10}$.

La trama que vincula a Carpentier con la música es aún más tupida. Por si fuera poco, además de su dedicación literaria, la labor intelectual de Carpentier se extiende también al ámbito de la musicología. En 1946 publica La música en Cuba, un erudito estudio que explora las vertientes española, indígena y negra que confluyen en la singular música de la isla. Tanto Müller-Bergh (1972: 50-51) como Acosta subrayan el alcance de este trabajo en su disciplina y su relevancia en la formación del universo narrativo del escritor; Acosta ve en él "un auténtico semillero de donde saldrán personajes, temas, motivos secundarios y, sobre todo, esa ambientación tan bien lograda de los siglos XVI, XVII, y el punto de viraje histórico situado en la confluencia de los siglos XVIII y XIX en todo el ámbito del Caribe" (Acosta 1981: 29). Por otra parte, entre 1951 y 1959, Carpentier escribe en El Nacional de Caracas la sección "Letra y Solfa", donde alterna artículos de tema literario con otros sobre cuestiones musicales. Una lectura del aspecto musical en el conjunto de su escritura permite a Carlos Villanueva afirmar que "la gigantesca aportación musical de Carpentier supone, básicamente, una inmensa crónica fraccionable en temas, momentos, géneros, según el medio para el que escribe y el tipo de receptor" (Villanueva Abelairas 2011: 907).

\footnotetext{
${ }^{10}$ A partir de las conclusiones que equiparan la estructura de El acoso a la de una sonata, Acosta conecta cada obra del escritor con un esquema musical que funcionaría como esqueleto: El siglo de las luces sería un poema sinfónico; Écue-Yamba-Ó, un libreto para una tragedia burlesca; El reino de este mundo, un ballet; El recurso del método, una ópera bufa; Los pasos perdidos, una cantata; Concierto barroco, un concerto grosso (Acosta 1981: 23).
} 
El propio escritor aviva la interpretación de su obra literaria como una escritura poderosamente tutelada por la música. En las "Confesiones sencillas de un escritor barroco", se expresa de manera tajante a este respecto: "Considero que todo escritor debe tener conocimiento de un arte paralelo, pues eso enriquece su mundo espiritual. La música está presente en toda mi obra” (Arias 1977: 67). Tres ańos antes, en una entrevista publicada en la Revista Mexicana de Cultura en 1974, habla del "compositor malogrado que, desde la adolescencia, convive en mí con el escritor” (Carpentier 1987: 193) ${ }^{11}$.

Sin embargo, sabemos de los peligros de asumir las declaraciones de los autores sobre su propia obra como pruebas irrefutables; las más de las veces responden a anhelos y lecturas subjetivas, cuando no a maniobras motivadas por intereses velados. Prevenido contra este peligro y contra la transmisión de planteamientos superficiales, Gabriel María Rubio Navarro lleva a cabo un escrupuloso estudio en el que somete a examen la consistencia de la interpretación musical de la narrativa carpenteriana y detecta un buen número de ideas inexactas y, sin embargo, poderosamente arraigadas. De este modo, evidencia que lo que tradicionalmente se ha considerado una correspondencia sólida no pasa muchas veces de metafórica analogía.

En Carpentier encontramos numerosos indicios de la aplicación de técnicas compositivas, pero también los encontramos de algo esencial: las novelas del cubano son literatura, no intentan ser música. Muchos críticos han intentado hacer oír en sus novelas sinfonías de Beethoven o fugas de Bach, convirtiendo a Carpentier en un hábil imitador de formas musicales. Estas líneas han probado que eso no es así. Sin embargo, sus novelas sí incorporan elementos musicales. La musicalidad se construye a partir de repeticiones de palabras o sintagmas, de símbolos convertidos en leitmotivs, y de todo un mundo sonoro concebido como telón de fondo de la narración (Rubio Navarro 1998: 230).

Si en el plano estructural la solidez de la consonancia música/escritura se tambalea, no ocurre lo mismo en los terrenos fónico, simbólico o temático. En consecuencia, la propuesta de Rubio Navarro se dirige a la integración del estudio de la música en el más amplio mundo de los sonidos: "Silencio, sonido y música, son partes inseparables de una ambientación sonora patente en todas las narraciones de Alejo Carpentier. No se puede hablar de música, o de canciones, o de instrumentos musicales en sus novelas, dejando a un lado todo un mundo de 'ruidos' indeterminados' (Rubio Navarro 1998: 157).

\footnotetext{
${ }^{11}$ Son muchas más las ocasiones que el autor aprovecha para conectar su escritura con el arte musical. En otra entrevista, a la pregunta de qué es lo que más le interesa tras la creación literaria, Carpentier responde: "La música, indudablemente. Mi padre fue un excelente violonchelista, antes de ser arquitecto. Una abuela mía, magnífica pianista, era discípula de César Franck. La práctica de la música fue cosa corriente en mi familia desde hace varias generaciones. De ahí que yo estudiara la técnica musical con suma facilidad, apasionándome, desde la adolescencia, por los problemas del arte sonoro" (El Nacional, Caracas, 16 de julio de 1956; cit. en Carpentier 2007: 9).
} 
A partir de todo lo anterior, la lectura de "España bajo las bombas" se ilumina con la teoría y a su vez la refrenda. En cierto sentido, la diferencia fundamental de este reportaje con las crónicas de otros corresponsales de la Guerra Civil Española está en el sonido: Carpentier, en lugar de observar la guerra, parece escucharla ${ }^{12}$. A lo largo de las páginas publicadas en Carteles, el escritor recrea un mundo auditivo de minuciosos matices, donde lo que percibe el oído predomina muchas veces sobre lo que se ve, se palpa, se olfatea o saborea. La música surge de todas partes en los momentos de paz ${ }^{13}$. Así, a la llegada a España se describen unas playas lamidas por "las olas musicales del Mediterráneo" (Carpentier 1979: 137). En Minglanilla, donde los intelectuales extranjeros viven algunos de los momentos de máxima emoción, el silencio es roto "tan sólo por el rasgueo metálico de esa mandolina que cada cigarra lleva prendida en su cintura" (Carpentier 1979: 160); también en ese pueblo destacan las voces "frescas, de niños, cuyo timbre cristalino se armonizaba con el manso correr de una fuente (Carpentier 1979: 160). En Madrid, los trabajadores no provocan un ruido estrepitoso al golpear las latas, sino que hacen rodar "latas filarmónicas a lo largo de las aceras" (Carpentier 1979: 168).

En la guerra, las canciones tienen siempre un papel destacado: ya sea para alentar las tropas o para cifrar la esperanza de la retaguardia, es frecuente encontrarlas en textos sobre experiencias bélicas ${ }^{14}$. Como tantos otros visitantes de la guerra, Carpentier retrata con sorpresa y fascinación la entereza de los habitantes de Madrid frente a los bombardeos sin tregua: "Una canción ha surgido -canción escrita con sangre. Y esta canción la saben cantar hoy todos los hombres que viven en el territorio de la Espańa republicana: Madrid

\footnotetext{
${ }^{12}$ Mención aparte merece desde luego su estilo singular, forjado sin duda gracias al dominio de un lenguaje poderoso y exuberante pero también, para ser justos, a las condiciones de escritura: no bajo las bombas sino a posteriori, en la retaguardia de París, con la consiguiente serenidad para la reflexión y para el delicado ejercicio de lustrar las palabras.

${ }^{13}$ Para proceder con coherencia y asumiendo la propuesta de Rubio Navarro de la existencia de un "fondo sonoro", cabe seńalar que son elevadísimos los ejemplos de las alusiones a sonidos a lo largo de "España bajo las bombas", aunque no siempre sean estos de carácter musical (no entro, por su especificidad y por desviarse de la lectura, en los matices de diferenciación de "ruidos reales", "ruidos musicales" y "símbolos sonoros"). Ejemplos: "Tren destartalado [...] cuyas ruedas gimen lamentablemente a lo largo de los rieles" (136); "Si oyes las sirenas, acuéstate contra una pared" (140); "sentía el ruido leve, de abanico, de los trigos segados por las ametralladoras" (146); "la formidable explosión que dejó medio edificio al aire libre" (149); "ruido que hiere mis oídos por primera vez" (150); "De pronto, una explosión sorda, subterránea, formidable golpe de ariete en la corteza del suelo, hace temblar las paredes del hotel" (151); "Suenan sirenas anunciadoras de paz" (152), etc. Más allá de Alejo Carpentier, sería posible aplicar este ejercicio a otros autores extranjeros de la Guerra Civil Espańola: el comunista londinense John Sommerfield, por ejemplo, habla en su crónica Volunteer in Spain (1937) de una "historia natural de la guerra" a través de los sentidos (Binns 2004: 50).

${ }^{14}$ Para un completo análisis de la música popular durante la Guerra Civil Espańola, véase el documentado trabajo de Ossa Martínez, quien, además de compilar y comentar un número abundantísimo de canciones, señala otros aspectos de interés, como la adaptación de temas populares a partir de las grabaciones de Lorca con La Argentinita, la edición de breves cancioneros con textos e incluso partituras y la relevancia de la música en el día a día de los combatientes.
} 
qué bien resistes / Madrid qué bien resistes [...]" (Carpentier 1979: 154-155). No obstante, Carpentier va más allá y registra un elevado número de gente cantando. En la carretera, se cruza con camiones cargados de "hombres que cantan alegremente. Soldados que van. Heridos que vienen" (Carpentier 1979: 159). En el pueblo de Minglanilla, los niños "vinieron a cantar debajo de nuestras ventanas" (Carpentier 1979: 161); la escena se repite en Madrid, donde otros nińos "juegan entre los escombros. Cantan" (Carpentier 1979: 170). En el Hotel Victoria de la Plaza de Santa Ana en el que se hospeda, también el botones "va cantando distraídamente, a media voz" (Carpentier 1979: 167); no importa que justo enfrente una iglesia haya sido arruinada por los bombardeos. La canción: otra de las formas de la resistencia.

Sin embargo, lo más interesante de todo es la constatación de que también los estruendos de la guerra son traducidos al lenguaje musical por el oído adiestrado de Carpentier. De este modo, inaugura su texto con una promesa a los lectores: "trataré de haceros sentir el crescendo de esa emoción, que se amplifica como un regulador de partitura musical, hasta alcanzar el Fortissimo gigantesco, inhumano y tan humano, de Madrid" (Carpentier 1979: 134). La tensión narrativa del relato se anuncia asimilada a las claves de una composición. El orden de las detonaciones de bombas en Barcelona parece ostentar una de las cualidades fundamentales de la música, pues se hace referencia "al ritmo de explosiones que parecen venir de abajo" (Carpentier 1979: 141). Sobre la ciudad de Valencia los bombarderos dejan caer sus bombas y el sonido de la caída en el aire se asemeja al que produce un instrumento de viento de timbre a todas luces amenazante: "Zumbido de motores de aeroplanos, acompañados de un extrańo silbido intermitente, como notas picadas de un flautín agudísimo" (Carpentier 1979: 150). En cambio, el ruido de los cañones que los defienden es comparado con las modulaciones de un pájaro: "Vuelve a oírse el gorjeo incisivo de los cañones antiaéreos" (Carpentier 1979: 151).

Dos imágenes de un alto contenido simbólico clausuran el relato y retoman la declaración inicial, proporcionando al reportaje una estructura circular. En la primera de ellas, Carpentier refiere cómo un grupo de intelectuales (compuesto por Félix Pita Rodríguez, Pablo Neruda, César Vallejo, Octavio Paz y él mismo) se acerca al frente de Madrid. Al recorrer Alberto Aguilera y el Paseo de Rosales, Carpentier y los demás encuentran la destrucción, una destrucción que también alcanza el reino de la música, aniquilado por la guerra: " $¿ Y$ el quiosco de la Moncloa, donde tantas veces oí ejecutar prestigiosamente el Andantino de la Séptima Sinfonía? Está ahí, hecho una maraña de alambres y de barrotes, en su media plataforma donde las granadas hicieron carambolas de fuego. A su alrededor yacen los postes del alumbrado, como plantas derribadas por un ciclón" (Carpentier 1979: 175).

La última imagen es sin duda más esperanzadora. En un paseo por el mismo barrio de Argüelles, Carpentier asiste a una escena que, si no fuera por la acumulación de fotografías insólitas de la guerra, parecería fruto de una alucinación provocada por la melomanía del escritor: "en el medio salón de una media casa, bajo un medio techo, junto a una media ventana, una muchacha sonriente y linda hace sus ejercicios en un medio piano" (Carpentier 1979: 176). Sin embargo, el piano de Argüelles no es el mismo caso que el del 
quiosco de Moncloa, pues pese a haber sido cercenado, el fuego no ha terminado con él: "Pero el estrépito infernal de cuatrocientos obuses cayendo sobre la ciudad no borrará de mi memoria el sonido conmovedor del pobre piano herido - piano del barrio de Argüelles-, cuya canción en clave sol ha sido para mí una expresión simbólica de la resistencia de Madrid" (Carpentier 1979: 176) ${ }^{15}$.

El análisis permite extraer algunas conclusiones en función de los textos con los que se confronten los resultados. Por un lado, considerando el conjunto de la producción carpenteriana, queda demostrado que para estudiar en ella la función protagónica de la música es necesario recorrer las crónicas periodísticas, donde se experimenta de manera incipiente lo que más tarde constituirán estrategias y recursos característicos del autor en su obra narrativa. En este sentido, se podría afirmar junto con Rubio Navarro que "la década de los treinta representó para Carpentier la toma de conciencia del poder evocador del sonido, y que su incorporación al mundo narrativo se produjo gradualmente, investigando las posibilidades literarias de este elemento" (Rubio Navarro 1998: 165). Por otro lado, si junto a "España entre las bombas" se colocan las demás crónicas de la Guerra Civil Española, la conclusión a observar es otra: que pese a cierta rigidez y a algunos lastres del género -como su carácter instrumental o su maniqueísmo-, hay lugar en él para que cada escritor imprima su huella. Los vestigios que deja Carpentier en esta hipotética antología han de leerse convirtiendo momentáneamente los renglones de la página en las líneas del pentagrama.

\section{Segundo MOVIMiento: LáGrimas en Minglanilla}

En la colisión de la guerra y la literatura, la segunda vuelve con frecuencia la mirada sobre sí misma. Como se verá a continuación, las páginas de "España bajo las bombas" contienen algunas reflexiones y deslizan valiosas pistas para comprender el valor que otorga Carpentier a la escritura en tiempos de guerra.

\footnotetext{
${ }^{15}$ Esta impactante escena de la mujer tocando el piano afecta profundamente a Carpentier. Tanto es así que al poco de regresar a París escribe una carta (con fecha de 10 de agosto de 1937) al dadaísta Georges RibemontDessaignes en la que reincide sobre ella. El documento tiene un alto valor no sólo por su contenido, sino porque además es prácticamente desconocido: "Acabo de regresar de Espańa. Es decir, del infierno de Madrid donde viví veinte días. Mi querido Ribemont, cuando le hablaba de España aún no sabía lo que era. Es cien veces peor de lo que nos cuentan los periódicos [...]. ¡Madrid vive bajo el obús! ¡Caen 800 cada día! ¡Por la mañana, por la tarde, por la noche! [...] Y la vida continúa. Las mujeres son bellas, ¡y están bien peinadas! La vida adquiere allá una magnitud inimaginable [...]. Brunete huele a muerte a ocho kilómetros. [...] Vi en la calle Alberto Aguilera, en Madrid, a una niña tocando a Chopin en un piano al que sólo que quedaban [sic] las teclas de la clave de sol -porque el resto del piano y de la casa habían sido eliminados por un obús-. Siento, Ribemont, que esta carta será de una incoherencia rara. Pero el caso es que traigo desde España impresiones personales que pueden llenar un volumen [...]. Usted no sabe el trastorno que este viaje ha podido provocar en mi vida" (Vásquez 2005: 254). La traducción de la carta es de Carmen Vásquez, quien lo saca a la luz; el original en francés, al que no he podido acceder, se encuentra en la biblioteca Jacques Doucet de París.
} 
Uno de los momentos más emotivos para la delegación de escritores es el encuentro de Minglanilla, pueblo de la provincia de Cuenca donde improvisan un alto en el camino ${ }^{16}$ : "Allí, los hombres más endurecidos, los filósofos más habituados a considerar elementos humanos como factores de especulación, los escritores más decididos a no dejarse conmover, sintieron correr por sus mejillas las lágrimas reprimidas durante años" (Carpentier 1979: 160). El episodio, generosamente detallado en el reportaje de Carpentier ${ }^{17}$, ofrece un par de claves para interpretar cuál es la imagen del intelectual en la época.

Carpentier recobra la estampa poderosa de un niño, huérfano y desamparado, que ha escrito sobre uno de sus brazos el mantra de la resistencia: “No pasarán!” (Carpentier 1979: 162) ${ }^{18}$. La imagen ostenta un alto poder simbólico, tanto para los escritores que la presencian como para el lector de la crónica. Pero ¿por qué? En un primer nivel, pone de manifiesto el alcance de la unidad y la fe en la zona republicana, donde incluso los niños están politizados y llevan grabadas las consignas (lo que al mismo tiempo, desde otra óptica, puede ser interpretado como una prueba de los estragos de la propaganda $)^{19}$. No obstante, en un nivel más profundo la imagen está hablando de la escritura sobre el soporte del propio cuerpo, cuya sacralidad es vulnerada por la tinta. La guerra, entonces, escribe sobre el cuerpo humano, al que de algún modo también hiere con otra de sus armas: la palabra.

Sin embargo, la escena más reveladora tiene lugar cuando una anciana le dice a Carpentier unas palabras que (según él mismo afirma) nunca podrá olvidar: “¡Defiéndannos, ustedes que saben escribir!...”. Lo que a continuación confiesa el escritor es uno de los núcleos de significado de su texto:

\footnotetext{
${ }^{16}$ ¿Es Minglanilla la Arcadia? Podría pensarse, dada la identificación del pueblo castellano con un locus amoenus: "una plazuela polvorienta y resplandeciente de luz, guarnecida de unos pocos árboles sedientos, envidiosos del relativo frescor de los soportales... Sobre los techos, llanuras hasta el infinito. Trigales maduros y perfumados, bajo un cielo sin nubes. [...] aquella paz de siesta se iba poblando de voces. Voces frescas, de niños, cuyo timbre cristalino se armonizaba con el manso correr de una fuente" (Carpentier 1979: 160).

${ }^{17}$ Alejo Carpentier no es el único: numerosos intelectuales destacan en sus ponencias, artículos o diarios la emoción vivida en el pueblo de Cuenca. Entre los hispanoparlantes, se refieren a Miglanilla los cubanos Juan Marinello y Nicolás Guillén, la mexicana Elena Garro, el chileno Alberto Romero, los españoles Corpus Barga y María Zambrano; entre los extranjeros, cabe citar a los ingleses Stephen Spender y Valentine Ackland, los franceses Julien Benda y André Chamson, el belga Denis Marion, los soviéticos Mijail Koltzov e Ivan Mikitenko (dramaturgo ucraniano), el estadounidense Malcolm Cowley y el enigmático chino Se-U. El artículo de Niall Binns, "Un descanso en el camino para los congresistas del '37: Minglanilla, lugar de epifanías", recoge abundantes testimonios e interpreta el alcance de lo que sucede (y lo que se recuerda) durante la inesperada visita a este "pueblo pobre, polvoriento pero pintoresco de Minglanilla" (Binns 2008: 66).

${ }^{18}$ Nicolás Guillén, en la ponencia que lee durante el Congreso en el Théâtre de la Porte Saint Martin de París el 16 de julio, también recuerda al niño tatuado de Minglanilla, aunque en su memoria son los dos brazos los que contienen mensaje (Guillén 1937; Aznar Soler 2009: 247-248).

${ }^{19}$ Conviene subrayar que la unidad antifascista que proclaman los participantes del Congreso no es tal en el verano de 1937. Desde los Sucesos de Mayo en Barcelona, el frentepopulismo está herido de muerte y las fuerzas republicanas españolas no pueden ocultar su división. No hay, sin embargo, en el reportaje de Carpentier atisbos del cisma que conducirá a la derrota.
} 
¡Nunca me sentí tan humillado como en aquel instante, dándome cuenta de lo poco que significa el "saber escribir" ante ciertos desamparos profundos, ante ciertas miradas de fe, ante el oscuro anhelo de mundos mejores que palpita en el alma de estos campesinos castellanos, para quienes -debo afirmarlo categóricamente- su adversario cobra figura de Anticristo...! (Carpentier 1979: 162) ${ }^{20}$.

Esta declaración demuestra que también Carpentier se ve afectado por el desorden más frecuente en los escritores en contacto con la guerra: el complejo de inferioridad ante el soldado, el miedo a que la escritura constituya una dedicación vergonzosa o un ocio malogrado, el sentimiento de culpa por sortear mediante el uso de la palabra la tarea que reclama a los hombres de su condición en tales circunstancias.

En este contexto de evaluación del acto literario, no puede resultar inocua, por tanto, la imagen de un libro horadado por las balas: "Su Góngora monumental sólo ha sufrido un percance; está atravesado de parte a parte por una bala" (Carpentier 1979: 172). Es el apartamento de Pablo Neruda, en la antaño resplandeciente Casa de las Flores, "hoy acribillado por los cascos de obús y la metralla", donde todavía se conservan "sus ediciones raras, sus máscaras javanesas, sus souvenirs de poeta viajero" (Carpentier 1979: 172); allí regresan los intelectuales, capitaneados por el chileno, en su visita al barrio de Argüelles ${ }^{21}$. Metáfora múltiple, el Góngora traspasado representa la cultura que castiga el enemigo, pero supone también un eficaz escudo contra los proyectiles ${ }^{22}$. El apetito de la muerte subvierte

\footnotetext{
${ }^{20}$ La trascendencia de los sucesos de Minglanilla conlleva que la imagen de España quede asociada con este pueblo en la mentalidad de Carpentier; así, incluso alcanza su obra de ficción al menos dos veces en los años setenta. En La consagración de la primavera es en Minglanilla el lugar donde Enrique ve por última vez a Ludwig Renn: "siempre de torso desnudo en la canícula de la llanura castellana -creo que lo vi por última vez en Minglanilla, subiendo hacia un frente que se nos iba quebrando" (Carpentier 2008: 221). También en Concierto barroco hay un guińo al pueblo castellano, que es nombrado ya sin relación alguna con la guerra: el indiano, al recorrer España fugazmente, pernocta en "las posadas blancas -cada vez más blancas- de Tarancón o de Minglanilla” (Carpentier 1974: 30). La vida del escritor permea su obra.

${ }^{21}$ La siniestrada Casa de las Flores de Neruda es un símbolo de los destrozos de la guerra en la esfera intelectual. También vuelve a ella el poeta chileno Juvencio Valle, otro corresponsal hispanoamericano de la Guerra Civil Española, y la encuentra "completamente agujereada. Un balcón le colgaba hacia el vacío: al menor soplo de viento oscilaba como un péndulo y parecía que se iba a desprender. [...] ¡Ah, pero allí no había ya flores ni perros ni chiquillos! Las lagartijas tenían en ella su morada y se calentaban tranquilamente al sol como en la tierra de nadie" (Olivares Briones 2001: 505).

${ }^{22}$ En La consagración de la primavera hay un fragmento que ilustra esta relación de los libros con las balas: "Sí. Había estado en la defensa de Madrid. En los peores tiempos. Los de la Ciudad Universitaria. Cuando el Comuna de París ocupó Filosofía y Letras, y se hicieron parapetos con libros: de Kant, Goethe, Cervantes, Bergson... y hasta Spengler. Mejor cuando eran autores de muchos tomos, porque a Pascal, a San Juan de la Cruz, a Epicteto, los hubiesen traspasado con una sola bala de fuerte calibre. Lo que allí servía eran los setenta y cuatro tomos de Voltaire, los setenta de Víctor Hugo, las obras completas de Shakespeare, la Biblioteca de Autores Españoles de Rivadeneyra, empastados y en papel de mucho cuerpo... 'Ahí supe, de bruces entre bibliotecas transformadas en parapetos, que las letras y la filosofía podían tener utilidad ajena a la de su propio contenido... Ahí, metiendo el canón del fusil entre tomos de Galdós -otro autor muy apreciado, por prolífico, en tales
} 
muchos valores y la característica primordial del libro es, en este caso, su materialidad ${ }^{23}$. Las reflexiones de Eliades Acosta van en esta dirección: "Desacralizado el libro, develada la misión terrenal del escritor, del artista, del intelectual en tiempos de barbarie y muerte, reconoce, no obstante, Alejo Carpentier que la cultura salva y defiende la vida, y que, como comprendieron los brigadistas parapetados en Filosofía y Letras, un tomo de Voltaire puede salvar la vida" (Acosta Matos 2004: 18-19).

Si por un lado es cierto que en el contexto de la guerra se produce una depreciación de las categorías de intelectual y escritor, trasladado su prestigio al combatiente, que pone su vida en juego, se reconoce simultáneamente una idea contrapuesta: la reivindicación de esas categorías, o cuando menos la asunción con orgullo de lo que con pompa y sin recato se denomina la misión del escritor. El resultado es la coexistencia de las dos tensiones contrarias y de algún modo no excluyentes.

Parece claro que la politización de los años treinta ha reconfigurado la definición de escritor, muy alejada ya de cualquier tentativa torremarfilista. El literato adquiere un compromiso con el pueblo y limpia la mala conciencia con su participación en la actividad política, su inclusión en la colectividad. En "España bajo las bombas" se relata cómo los escritores son llevados a las oficinas del Comisariado de Propaganda en Barcelona para hablar a través de la radio, gesto que resulta ya significativo de la función de los intelectuales ${ }^{24}$. Ante el micrófono, tras la intervención de Juan Marinello en catalán, André Malraux, "uno de los más altos valores de la literatura mundial” ${ }^{25}$, se sirve de una anécdota:

Un día en que los obuses caían sin tregua sobre Madrid [...] me encontré en la Gran Vía con un individuo que llevaba un largo rollo de papel debajo del brazo,

momentos- pude decir como Mallarmé: La chair est triste, hélas! et j'ai lu tous les livres..." (Carpentier 2008: 118). Sobre el papel desempeñado por los libros en la lucha de la Facultad de Filosofía y Letras hay un bello mosaico de testimonios. Dan Kurzman relata el momento en el que "cientos de libros [son] descubiertos en la biblioteca del sótano" y a partir de ahí sirven para construir improvisadas trincheras. Como señala Carpentier, los libros más gruesos son los más anhelados; Bernard Knox ahonda en el tema y aporta incluso el dato exacto de que "el grado de penetración de las balas llegaba aproximadamente hasta la página 350". Pero los libros se convierten en un escudo que no es solamente físico: así lo demuestra John Sommerfield, capaz de suspender los disparos y los obuses para sumergirse "en otro lugar, en otro tiempo" mediante la lectura de un ensayo de Thomas de Quincey sobre Wordsworth y Coleridge. Todas estas anécdotas fascinantes son recogidas por Marta Torres Santo Domingo (2005: 259-285).

${ }_{23}^{23}$ iDe qué poco servirían los modernos libros electrónicos a la hora de levantar un parapeto...!

${ }^{24}$ En esos términos se expresa, por ejemplo, André Chamson en una cita rescatada por Carpentier: "Añado que nuestra función de escritores nos obligaba a realizar ese viaje..." (Carpentier 1979: 135). No pueden ser los escritores individuos separados, sino que, como el resto de miembros de la sociedad a la que pertenecen, tienen una tarea que desempeñar en relación con ella.

${ }^{25}$ Para ahondar en el compromiso de los escritores franceses con Espańa y, particularmente, su papel en el Congreso de 1937, el artículo de Maryse Bertrand de Muñoz (2008) aporta datos sobre Malraux, Benda, Aragon y Chamson. 
y andaba tranquilamente por los lugares más expuestos, sin pensar en el peligro. Intrigado, lo seguí. ¡Un manuscrito de metro y medio de ancho es cosa que siempre ha de interesar a un escritor! Le pregunté lo que era aquello. Me respondió: "¡Es papel encolado, pues quiero cambiar los papeles que tapizan mi habitación!...” (Carpentier 1979: 142).

Los papeles pintados para cubrir las paredes de la torre de marfil: lo que a primera vista parece a Malraux la presencia enigmática de un valiente escritor que pone su vida en juego (¿para salvar, quizá, unos manuscritos de incalculable valor?) se revela como la actitud censurable de quien evade el dolor y la guerra para ceder a preocupaciones de orden estético. Malraux concluye subrayando la idea que el lector ha podido imaginar: "hay demasiados intelectuales que sólo piensan en cambiar los papeles que tapizan sus habitaciones" (Carpentier 1979: 142).

En consecuencia, el prototipo de escritor puede ser el novelista alemán Ludwig Renn, quien, además de escribir, combate ${ }^{26}$ (hombre de armas y letras, como demanda el ideal renacentista). Renn es un intelectual próximo a la cincuentena, pero Carpentier, deslumbrado, roza la hipérbole en su descripción, que hace pensar más bien en un joven apolo (o un herrero velazqueño) que en un escritor maduro; parece acertado entonces entender esa descripción física como un correlato de la moral:

Dotado de una extraordinaria distinción física, Renn es uno de los hombres más afables y sencillos que pueda imaginarse. Habla el castellano con toda perfección y siempre tiene una palabra cordial a flor de labios. Aquella tarde andaba con el torso desnudo, musculoso y quemado por el sol. Una extraordinaria juventud brillaba en sus ojos azules, a pesar de que sus cabellos grises, cortados casi a rape, revelaban una plena madurez (Carpentier 1979: 164) ${ }^{27}$.

A continuación, Carpentier le confiesa su admiración "porque es usted uno de los pocos escritores de nuestros tiempos que hayan sabido realizar paralelamente su vida y su obra, haciendo de la vida obra, y de la obra vida" (Carpentier 1979: 164). En esta estructura de quiasmo se cifra el amplio proyecto estético e ideológico que abrazan muchos intelectuales

\footnotetext{
${ }^{26}$ Recuérdense las palabras de Ludwig Renn en su ponencia: "Nosotros, escritores que luchamos en el frente, hemos dejado la pluma porque no queríamos escribir historia, sino hacer historia. [...] Muchos creyeron que la pluma era innecesaria; al contrario, para nuestra causa es necesario no solamente combatir con el fusil en la mano, sino con la pluma. Es por eso por lo que me dirijo a vosotros, venidos del mundo entero, para que seáis nuestros representantes: Ya que nosotros no tenemos tiempo de escribir, hacedlo vosotros. Os ofrezco mi pluma y creedme que no es ningún disgusto para mí. [...] Combatid con la pluma, con la palabra, con vuestras posibilidades, pero combatid" (Aznar Soler 2008: 10).

${ }^{27}$ Cotejando esta descripción de Ludwig Renn con la que lleva a cabo Carlos Montenegro, se obtienen disímiles resultados. Montenegro destaca más bien sus "brazos larguísimos" y lo describe como alguien "muy alto y delgado" a quien "el castellano se le hace más difícil por la excitación" (Montenegro 1937: 10).
} 
ante el nuevo momento. Carpentier, el escritor que da sus primeros pasos ${ }^{28}$, encuentra su modelo en el escritor consagrado, hombre de acción que conjuga la experiencia vital con la literaria. Renn le contesta que "es aquí, en el suelo de España, donde mejor he sentido que mi vida y mi obra podían constituir un todo indivisible" (Carpentier 1979: 164), tras lo que Carpentier construye otro quiasmo que es en el fondo una pregunta retórica: “¿El novelista lucha y el combatiente escribe?” (Carpentier 1979: 164). Lo que se desprende del encuentro con Ludwig Renn en el texto de Carpentier es que la Guerra Civil Espańola constituye una llegada, el final de un camino que durante algunos años ha conducido a los escritores a cuestionarse la validez de su oficio y desemboca en el convencimiento de que sólo es posible una literatura vinculada íntimamente a la política.

¿Cuál es, por tanto, la manera más adecuada de contar la guerra de España? Carpentier se plantea la misma pregunta al comienzo de su reportaje y anticipa la posible crítica que pudiera hacérsele por recurrir a un género que responde a la subjetividad del escritor. Su primera intención, según afirma, habría sido ofrecer glosas políticas y relaciones austeras, vetando de este modo el protagonismo a las veleidades del yo, pero en ningún caso "un reportaje... ya que el 'reportaje' implica ciertas concesiones a un pintoresquismo descriptivo y anecdótico que se me antojaba fuera de lugar en momentos tan dramáticos, tan patéticos, como los que está viviendo la España de hoy" (Carpentier 1979: 133). Sin embargo, Carpentier llega a la conclusión de que las situaciones dramáticas no caben o no pueden ser relatadas en un estilo contenido; de que la contemplación de espectáculos repletos de humanidad relega la "lógica del pensamiento" para dar paso a "la lógica del corazón, que es, al fin y al cabo, la única eficaz en circunstancias como las que hemos conocido" (Carpentier 1979: 134-135). Si bien cada escritor descubre una solución para dar cuenta de la guerra, Alejo Carpentier halla en la subjetividad del reportaje el modo más fidedigno de narrar y de este modo acometer la misión del intelectual.

Por otra parte, el valor de la escritura queda de manifiesto mediante la intercalación de textos de otros autores; en este caso, el "mosaïque de citations" del que habla Kristeva (1978: 85) es literal y la intertextualidad, en lugar de tender hacia el encubrimiento, se expresa con elocuencia en su desnudez. Además de los ya referidos André Malraux y André Chamson, a quien Carpentier cede la palabra media decena de veces (Carpentier 1979: 135, 139-140, 145, 158, 161), hay lugar para la intervención de los que, afirma el cubano, "supieron plasmar, mejor que yo, una frase o una emoción" (Carpentier 1979: 134-135): Corpus Barga recoge en un pormenorizado relato el encuentro en Minglanilla entre una escritora inglesa y una campesina castellana (Carpentier 1979: 162-163) ${ }^{29}$; y el romancero de la guerra encabeza diferentes secciones, ya sea con la firma de sus autores, como Emilio Prados, Rafael Alberti y José Moreno Villa, o en su variante anónima. Este diálogo con otros escritos responde a una suerte de proyecto tácito de erigir una escritura de la guerra,

\footnotetext{
${ }^{28}$ Quizá convenga recordar que la única novela que ha publicado hasta la fecha es Écue-Yamba-Ó, cuatro años atrás, y tardará muchos ańos en volver a publicar alguna obra estrictamente literaria.

${ }^{29}$ La escritora inglesa ha de ser Sylvia Townsend Warner o Valentine Ackland (Binns 2008: 67).
} 
manifestado en la reiteración del propio romancero, y al mismo tiempo responde a la voluntad (política) de integrar una colectividad tanto en el plano vital como en el estético ${ }^{30}$.

\section{CODA: EL ARCHIVO Y LAS RELECTURAS}

Como ya ha sido señalado, La consagración de la primavera recurre a "España bajo las bombas" para construir la primera parte de la novela, que gira en torno a la Guerra Civil (Gnutzmann 1986; Rodríguez Puértolas 1979: 14). Más de cuarenta años después, Carpentier desempolva su vieja crónica para trasladar la historia "verídica" que allí cuenta al reino de la ficción. El polvoriento recorte de prensa se convierte en un renovado palimpsesto. Las similitudes y variaciones, los calcos lingüísticos y la repetición de escenas, ya han sido convenientemente señalados por parte de la crítica. Para poner un ejemplo, el cotejo de los relatos del viaje en tren a través del túnel que funciona como frontera y la posterior llegada a Port Bou, desde la óptica del personaje Carpentier en 1937 y de Véra en 1978, revela la irrefutable filiación de ambos textos.

La consagración de la primavera se explica a sí misma en un instante de alta significación. Enrique, el combatiente cubano que en 1937 ha peleado en España, es herido en la pierna, la "misma que fue herida en España" (Carpentier 2008: 523) ${ }^{31}$, en Playa Girón en 1961. Poco antes de ese momento, la tensión narrativa va aumentando: "Esto, lo conozco. Lo he sentido, olido, padecido, hace ya más de treinta años...”. En ese momento, se reencuentra con su amigo y compatriota Gaspar, un músico que ha conocido en la Guerra Civil Española, y ambos protagonizan el siguiente intercambio: "Mi hermano!' -me grita el encaramado, sacándose un tabaco de la boca. - ¡Gaspar!' - ¡S'í! ¡Aquí! ¿Y tú?’ - ¡Aquí!’ -'Como en Brunete'. -'Pero allá la perdimos’. -‘¡Aquí la ganaremos!' -‘Patria o muerte!' -‘Patria o muerte!' - 'Nos vemos después'. - 'Nos vemos después' - repite la voz de Gaspar que ya se aleja" (Carpentier 2008: 521) ${ }^{32}$.

\footnotetext{
${ }^{30}$ En la novela La consagración de la primavera hay un eco de esta forma de proceder mediante la inserción de fragmentos de crónicas de Raúl González Tunón -otro poeta corresponsal de la guerra española- en el relato de Vera, que hojea la revista Hora de España: "Y me decía ahora, en su prosa, el emocionado testigo argentino: 'Con decir: Madrid, uno siente gusto a sangre, a tierra, y eso es bien simple y verdaderamente original [...]. Abrí los ojos y nací a las cinco de la mañana. Desde que estoy en Madrid no había oído estruendo igual'” (Carpentier 2008: 148). Se trata de fragmentos de dos textos publicados en el número de junio de 1937: "De la muerte en Madrid” (González Tuñón 1937a) y "Sobre los obuses" González Tunón 1937b). Carpentier debió de obtener ese ejemplar durante su viaje en el mes de julio y lo rescataría décadas después para la redacción del libro. En cualquier caso, el recurso de la inserción de la crónica resulta llamativo al tener lugar en el género novelesco, y al repetir el esquema de diálogos intertextuales que ya él había propuesto en su propio reportaje.

${ }^{31}$ Otra huella del palimpsesto de la experiencia real: en 1937, Carpentier encuentra a un combatiente cubano herido en la pierna: "Nos enteramos que hay un cubano en uno de los pabellones. Herido en una pierna por la metralla”.

${ }^{32}$ El personaje de Gaspar ha de estar necesariamente basado en el músico Julio Cueva Díaz, que llega a España
} 
Una pregunta interesante podría vincularse a la reacción del propio escritor ante el material de su archivo cuando lo reabre tantos años después y lo lee bajo nueva luz. Sirva como apunte de esta reflexión la cala en dos figuras emblemáticas, muertas durante la guerra, cuya apreciación varía notablemente (en este caso, es amplificada) cuatro décadas más tarde. El tiempo, qué duda cabe, elabora las mayores reescrituras ${ }^{33}$.

En el verano de 1937, Pablo de la Torriente Brau es ya un mito: su transformación de corresponsal en miliciano y su caída en combate en los alrededores de Majadahonda en diciembre de 1936 lo han elevado a la categoría de mártir. La mayor parte de los escritores hispanoamericanos que ejercen como corresponsales (y notablemente los cubanos) sienten su presencia magnífica, su "gigante esqueleto" ${ }^{34}$, la huella constante de quien es convertido desde los primeros compases de la guerra en el gran mártir entre los intelectuales latinoamericanos. En este sentido, el texto de Carpentier revela otra singularidad: la única mención a lo largo de "Espańa bajo las bombas" a Pablo de la Torriente puede pasar desapercibida: "Por su charla pasan evocaciones de Pablo de la Torriente Brau y de los comisarios políticos del frente que han sabido captarse no ya la admiración, sino el amor de sus soldados" (Carpentier 1979: 146). Mientras que en el resto de crónicas y artículos escritos por las mismas fechas su figura es invocada casi como una presencia tutelar, Carpentier pasa por encima sobre su nombre (¿se debe esta ligereza a su ausencia de Cuba desde 1928?). Sin embargo, en la reescritura de La consagración de la primavera décadas después, la figura de Pablo de la Torriente es considerablemente amplificada. En la playa de Benicassim, es recordado en una conversación entrecortada entre los cubanos Enrique y Gaspar, el francés Jean-Claude y el estadounidense Evan Shipman, amigo de Hemingway:

La cuestión es ganar esta guerra, porque cuando la hayamos ganado, será más fácil hacer una revolución en Cuba. Así lo entendía Pablo de la Torriente Brau... / quién / uno de los mejores escritores jóvenes de mi país; su estilo tenía muchos paralelos

en los primeros meses de 1936 y se alista para combatir junto a la República. Carlos Montenegro lo conoce cuando viaja a España como corresponsal y lo menciona en una de sus crónicas.

${ }^{33}$ Años después, al valorar retrospectivamente la significación del Congreso de 1937, algunos de sus participantes reconsiderarán su papel en él desde un prisma ideológico muy diferente. En 1950, en el contexto de la Guerra Fría, se publica en Londres The God that Failed, libro conformado con los testimonios de seis intelectuales que ahora reniegan de su pasada militancia comunista; la mitad de ellos han participado de un modo u otro en la Guerra Civil Española: el "congresista" Stephen Spender, Arthur Koestler y Louis Fischer (además de André Gide, cuya ausencia en el Congreso se hace muy presente). Por otra parte, es conocida la reconversión ideológica de Octavio Paz pocos años después de la guerra, que se hace particularmente visible durante la conmemoración en Valencia del cincuentenario del Congreso de 1937. No es el caso de Alejo Carpentier, que no lleva a cabo una revaluación en este sentido; más bien al contrario, como ya ha sido señalado, Carpentier refrenda su postura vinculando la derrota de la Guerra Civil Española con el triunfo de la Revolución Cubana.

${ }^{34}$ La imagen corresponde a la "Elegía Segunda" que le dedica Miguel Hernández e incluye en Viento del pueblo: "Ante Pablo los días se abstienen ya y no andan. / No temáis que se extinga su sangre sin objeto, / porque este es de los muertos que crecen y se agrandan / aunque el tiempo devaste su gigante esqueleto" (Hernández 1989: 76). 
con el "estilo brutal" de tu amigo Hemingway, aunque no pienso que Pablo hubiese pensado en buscarse modelos literarios; era lo menos "literato" posible. Ni falta que le hacía: fue uno de los hombres mejores de mi generación... (Gaspar se había puesto de pie ya que su voz, ahora, me llegaba de arriba:) Cayó en Majadahonda, siendo comisario político; tuve el honor de dirigir la banda de la división 46, que tocó en sus funerales: sesenta músicos; la marcha esa, que es: reeee-laaaá, sol, fa, mi, re, laaaaá, sol, fa, mi, re, miiiiiiií, mi... ¡Ay, me acordé de mi banda! (Carpentier 2008: $150-151)^{35}$.

El pasaje, además de poner de manifiesto cierta experimentación en la disposición del diálogo y revelar una vez más la omnipresencia de la música en la prosa carpenteriana, introduce una imagen de Pablo de la Torriente acorde con su categoría legendaria: no sólo, dice Gaspar, "uno de los mejores escritores jóvenes de mi país", pese a ser (o precisamente porque es) "lo menos 'literato' posible", sino además "uno de los hombres mejores de mi generación”.

Con Federico García Lorca sucede algo muy similar. Inicialmente, es mencionado dos veces en la crónica, sin ningún epíteto, ninguna apostilla sentimental, tan sólo como el autor de la obra teatral Mariana Pineda (Carpentier 1979: 147, 157) ${ }^{36}$. Hacia el final, cuando se produce la entrada en Madrid, la alusión es más emotiva: "Ciudad [...] en que aún vaga -jtan evidentemente!- la vasta sombra de Federico García Lorca...!” (Carpentier 1979: 165). Esto es todo. No obstante, en La consagración de la primavera, al igual que sucede con Pablo de la Torriente, el nombre de Lorca adquiere resonancias magníficas; en realidad, "bastaba con decir 'Federico', pues Federico era, por antonomasia, Federico el Único, el Federico asesinado en Granada, y no había otro igual" (Carpentier 2008: 21). Entre las abundantes referencias al poeta de Granada, cobra particular fuerza la siguiente, donde Carpentier, por boca de Enrique, pone de manifiesto cómo el símbolo de su asesinato

\footnotetext{
${ }^{35}$ Este fragmento de la novela en la playa de Benicassim resulta particularmente memorable por una escena que además está directamente relacionada con la música: el capítulo 13 de la novela, íntegramente dedicado al multitudinario concierto de Paul Robeson, quien, como un director de orquesta, hace cantar al público la Internacional en sus distintos idiomas. Véra, narradora de este capítulo, experimenta así el concierto: "La música me llegaba a las entrañas, sin quebrar la coraza que me defendía de las palabras. Me sabía más fuerte que las palabras y nunca se me había conquistado con palabras. Pero, en el gigante Paul Robeson, hallaba yo otra fuerza de convencimiento, totalmente independiente de las palabras que acarreaba: fuerza del arte, de la elocuencia trascendida, magnificada, universal y sin tiempo, debidas a una presencia todopoderosa que, en terreno muy distinto, hubiese sido la de Anna Pávlova" (Carpentier 2008: 133-134). ¿Conocería Alejo Carpentier a Paul Robeson en España? ¿O más bien se basaría en la entrevista que le hace su compatriota Nicolás Guillén (1938)?

${ }^{36}$ Durante el Congreso de Escritores Antifascistas, tiene lugar en el Teatro Principal de Valencia una representación de esta pieza teatral. Manuel Altolaguirre es el director de una obra en la que el personaje de Don Pedro es encarnado por Luis Cernuda. Así lo reseña el número de agosto de 1937 de la revista Hora de España: "Y cuando en el segundo acto aparece Don Pedro, todos comprendimos quién había salido a escena realmente, ya que empleaba un amor y un respeto tan grandes en recitar los versos de su papel, que sólo un poeta, otro poeta, podía así decirlos" ("Representación de Mariana Pineda", 1937).
} 
desgarra el corazón de tanta gente, que siente su muerte en carne propia (y moviliza así innumerables simpatías para el bando republicano):

Y, ante el horror del mundo, el asesinato de Federico García Lorca. No era sino la muerte de un poeta -es decir, del más inerme, del más inofensivo, del menos peligroso, de todos los seres humanos. Y sin embargo, las balas sobre él disparadas penetraron también en las carnes de millones de hombres y mujeres en el mundo, como un aviso de próximos cataclismos que a todos nos afectarían por igual. (Carpentier 2008: 85) (37 $^{37}$

Lorca, el poeta luminoso, se convierte entonces en el símbolo fatídico de la guerra de España. Carpentier, tan vinculado a este país, vive en él días vibrantes que vuelca en su reportaje "España bajo las bombas", esencial para averiguar los entresijos del Congreso de Escritores Antifascistas - lágrimas incluidas- pero también para adentrarse en el taller del escritor: en el texto periodístico de 1937 ensaya las descripciones del mundo auditivo que vertebrarán toda su obra. Mientras otros dejan testimonio por escrito de las impactantes imágenes presenciadas en España, la pluma melómana de Carpentier prefiere guardar memoria de los sonidos de la guerra.

\section{OBRAS CITADAS}

Acosta, Leonardo. 1981. Música y épica en la novela de Alejo Carpentier. La Habana: Editorial Letras Cubanas.

Acosta Matos, Eliades. 2004. "Alejo Carpentier y la defensa de la República española”. Revista de la Biblioteca Nacional José Martí 95 (3-4): 13-19.

Arias, Salvador (comp.). 1977. Recopilación de textos sobre Alejo Carpentier. La Habana: Centro de investigaciones literarias, Casa de las Américas.

Aznar Soler, Manuel. 1987. I Congreso Internacional de Escritores para la Defensa de la Cultura: Paris, 1935. Valencia: Generalitat. . 2008. "La pluma y el fusil". República de las letras, Revista de la Asociación Colegial de Escritores de España 107: 9-14. . 2009. Materiales documentales del Segundo Congreso Internacional de Escritores para

\footnotetext{
${ }_{37}$ En un homenaje a Lorca celebrado en la Casa de la UNESCO de París en 1972, Carpentier glorifica el arquetipo de Lorca: "Cayó, y hoy conocemos -conoce el mundo- el peso de su sangre. Cargamos todos con el peso de su sangre. Dijo Aristófanes un día, en momento de seriedad, que ciertos versos pesaban tanto como un hombre muerto. Pero cuando el hombre muerto -o derribado- carga con el peso de versos que hallan eco en las entrañas de millones de hombres, su cuerpo pesa tanto que la tierra que lo recubre se hace poca para envolverlo. Y, a modo de epitafio sobre la tumba que no se hizo, que nunca alzó emblema ni cruz sobre su cuerpo, lo que queda es la mancha, la mancha que nos incumbe a todos [...] ¡Gracias a ti hemos sabido, Federico, cuánto pesaba la sangre de un poeta!..." (Castro 1986: 95-96).
} 
la Defensa de la Cultura (Valencia-Madrid-Barcelona-París, 1937). A Coruña: Ediciós do Castro.

Banville, John. 2012. Antigua luz. Madrid: Alfaguara.

Benítez Rojo, Antonio. 1983. “'El camino de Santiago', de Alejo Carpentier, y el Canon Perpetuus, de Juan Sebastian Bach: paralelismo estructural”. Revista Iberoamericana 49 (123-124): 293-322.

Bertrand de Muñoz, Maryse. 2008. "El compromiso de los intelectuales franceses y su participación en el Congreso Internacional de los Escritores Antifascistas de 1937: André Malraux, Julien Benda, Louis Aragon y André Chamson”. República de las Letras. Revista de la Asociación Colegial de Escritores de España 107: 23-36.

Binns, Niall. 2004. La llamada de España. Escritores extranjeros en la Guerra Civil. Barcelona: Montesinos.

2008. "Un descanso en el camino para los congresistas del '37: Minglanilla, lugar de epifanías”. República de las Letras. Revista de la Asociación Colegial de Escritores de España 107: 65-70.

Buscaglia, José. 2004. "1937: Carpentier y la lucha contra el fascismo”. Revista de la Biblioteca Nacional José Martí 95 (3-4): 24-29.

Carpentier, Alejo. 1937. "Los defensores de la cultura". Nuestra España. Boletín Semanal del Comité Ibero-Americano para la Defensa de la República Española 6: 1-2.

. 1938. “Abajo la inteligencia! ¡Viva la muerte!”. Mediodia, 3 (77): 14, 26. . 1939. "La muerte de Miguel Hernández". Carteles 34 (32): 36.

1974. Concierto barroco. México DF, Madrid, Buenos Aires: Siglo XXI Editores. . 1979. Bajo el signo de La Cibeles. Crónicas sobre España y los españoles, 1925-1937. Madrid: Nuestra Cultura.

. 1987. Obras completas, XII: Ese músico que llevo dentro, 3. La música en Cuba. México: Siglo XXI Editores.

2007. Ese músico que llevo dentro. Madrid: Alianza.

. 2008. La Consagración de la Primavera. La Habana: Letras Cubanas.

Castro, Eduardo (ed.). 1986. Versos para Federico. Lorca como tema poético. Murcia: Universidad de Murcia.

Chang, Leiling. 2002. "Una novela musical: Concierto barroco, de Alejo Carpentier". En: Alonso, Silvia (ed.), Música y literatura. Estudios Comparativos y semiológicos. Madrid: Arco Libros. 149-186.

Gálvez Acero, Marina. 1978. “Estructura musical del Concierto barroco de Carpentier”. En: XVII Congreso del Instituto Nacional de Literatura Iberoamericana, t. 1: El barroco en América, Madrid: Ediciones Cultura Hispánica del Centro Iberoamericano de Cooperación. 539-553.

Gnutzmann, Rita. 1986. "La consagración de la primavera: historia y ficción”. Anales de Literatura Hispanoamericana 15: 169-185.

González Tuñón, Raúl. 1937a. "De la muerte en Madrid”. Hora de España 6: 55-56. 1937b. "Sobre los obuses". Hora de España 6: 57-58. 
Guillén, Nicolás. 1937. "Nicolás Guillén”. Nueva Cultura 3 (4-5): s/n. . 1938. "Paul Robeson, al servicio del pueblo español”. Mediodía 3 (63): 10-11. Hernández, Miguel. 1989. Viento del pueblo. Madrid: Cátedra.

Kristeva, Julia. 1978. Semeotiké: recherches pour une sémanalyse. París: Éditions du Seuil. Montenegro, Carlos. 1937. "Una entrevista con Ludwig Renn". Mediodía 2 (43): 10, 18. Müller-Bergh, Klaus. 1972. Alejo Carpentier. Estudio biográfico-crítico. Nueva York: Las Americas Publishing Company.

Olivares Briones, Edmundo. 2001. Pablo Neruda: Los caminos del mundo. Tras las huellas del poeta itinerante II (1933-1939). Santiago de Chile: LOM.

Ossa Martínez, Marco Antonio de la. 2011. La música en la guerra civil española. Cuenca: Ediciones de la Universidad de Castilla-La Mancha; [Madrid]: Sociedad Española de Musicología.

Pino, Amado del \& Tania Cordero. 2013. Los amigos cubanos de Miguel Hernández. La Habana: Centro Cultural Pablo de la Torriente Brau.

"Representación de Mariana Pineda". 1937. Hora de España 8: 75-76.

Rodríguez Puértolas, Julio. 1979. "Nota previa" a Alejo Carpentier, Bajo el signo de La Cibeles. Crónicas sobre España y los españoles, 1925-1937. Madrid: Nuestra Cultura. 5-11.

Rubio Navarro, Gabriel María. 1998. Música y escritura en Alejo Carpentier. Alicante: Universidad, Servicio de Publicaciones.

Schneider, Luis Mario. 1978. II Congreso Internacional de Escritores Antifascistas (1937). Volumen I: Inteligencia y guerra civil en España. Barcelona: Laia.

Torres Santo Domingo, Marta. 2005. "Libros que salvan vidas, libros que son salvados: la Biblioteca universitaria en la Batalla de Madrid”. En: Calvo, Blanca \& Ramón Salaverría (eds.), Biblioteca en guerra, Madrid: Biblioteca Nacional. 259-285.

Vásquez, Carmen. 2005. "Las ficciones carpenterianas y sus fuentes bibliográficas españolas”. En: Baujín, José Antonio; Francisca Martínez \& Yolanda Novo (eds.), Alejo Carpentier y España. Actas del Seminario Internacional, Santiago de Compostela, 2-5 de marzo de 2004, Santiago de Compostela: Universidad. 243-269.

Villanueva Abelairas, Carlos. 2011, "El discurso musical como arma política en la obra de Alejo Carpentier”. Arbor, Ciencia Pensamiento y Cultura 187 (751): 905-916. 